\title{
Myoid Hamartoma of the Breast: A Case Report
}

\author{
Nah Ihm Kim, M.D., Ph.D. ${ }^{1}$, Min Ho Park, M.D., Ph.D. ${ }^{2}$, Ji Shin Lee, M.D., Ph.D. ${ }^{1}$ \\ ${ }^{1}$ Department of Pathology, ${ }^{2}$ Department of Surgery, Chonnam National University Medical School, Gwangju, Korea
}

\begin{abstract}
Breast hamartoma is a rare benign tumor that comprises lobular breast tissues with various admixtures of fibrous, fibrocystic, and adipose tissue. Hamartoma accounts for $0.7 \%-5.0 \%$ of all benign breast tumors. Myoid hamartoma is an extremely rare variant of mammary hamartoma characterized by the presence of smooth muscle component. Herein, we report a case of myoid hamartoma showing irregular margins and microcalcifications with a literature review.
\end{abstract}

Key Words: Breast, Histopathology, Myoid hamartoma

\section{INTRODUCTION}

Hamartoma of the breast is a rare, genetically linked, benign tumor that is characterized by an abnormal growth of mammary tissues including ducts, lobules, stroma, and adipose tissue [1,2]. Hamartoma accounts for $0.7 \%-5.0 \%$ of all benign breast neoplasms and they are further subclassified by the main mammary tissues affected [1,2].

Myoid hamartoma, first described by Davies and Riddell in 1973, is an extremely rare subtype that is characterized by the presence of histologically normal, but irregular, randomly distributed, smooth muscle cells [3]. The exact incidence of myoid hamartoma is not yet known, and there have been no more than 50 cases of myoid hamartoma described in the literature, mainly in case reports [3-13]. In general, it is considered that the smooth muscle component in myoid hamartomas originates from the myoepithelium, stromal myofibroblasts, walls of the blood vessels, or stromal stem cells [4-6,10]. Since the inception of regular breast cancer screening programs, the number of diagnosed myoid hamartomas is expected to increase; therefore, increased awareness of this rare disease is required to decrease the potential for pathological misdiagnoses. The use of excisional biopsies and immunohistochemical analyses are important to avoid confusion during the diagnosis of benign spindle cell tumors and tumor-like lesions including myoid hamartoma [14]. Herein, we report a case of myoid hamartoma

Correspondence: Ji Shin Lee, M.D., Ph.D.

Department of Pathology, Chonnam National University Hwasun Hospital, 322 Seoyang-ro, Hwasun-eup, Hwasun-gun, Jeollanam-do 58128, Korea Tel: +82-61-379-7072, Fax: +82-61-379-7079, E-mail: jshinlee@hanmail.net Received: Jun 1, 2020 Revised: Aug 15, 2020 Accepted: Aug 30, 2020 with a literature review focusing on the histopathological findings.

This study was approved by the Institutional Review Board at the Chonnam National University Hwasun Hospital (IRB No. CNUHH2020-108)

\section{CASE REPORT}

A 44-year-old woman presented with a 2-year history of a mass in her left breast. The mass seemed to increase in size approximately six months before presenting to the hospital. Mammography of the left breast revealed an oval calcified mass that was partly indistinct (Figure $1 \mathrm{~A})$, and ultrasonography revealed a $1.7-\mathrm{cm}$ irregular, indistinct hypoechoic mass with calcifications in the left breast (Figure 1B). Since the patient was living far from the hospital, she requested a surgical excision rather than a core-needle biopsy. After ultrasound-guided staining, local excision of the mass was performed. Macroscopically, the cut surface of the lesion revealed a yellow-white, non-encapsulated mass with slightly irregular margins. Microscopically, the mass comprised glandular and stromal elements in a disorganized pattern (Figure 2A). The glandular structures showed cystic changes, apocrine metaplasia, and adenosis. The dominant feature of the stromal elements was the presence of a fascicular formation of elongated spindle cells with incursions between some of the glandular structures (Figure $2 \mathrm{~B}$ and $2 \mathrm{C}$ ). These spindle cells were mingled with adipose and fibrous tissues. There was no evidence of necrosis and mitosis. Microcalcifications were present inside the stromal elements (Figure 2D). Immunohistochemical findings showed smooth muscle differentiation in the 

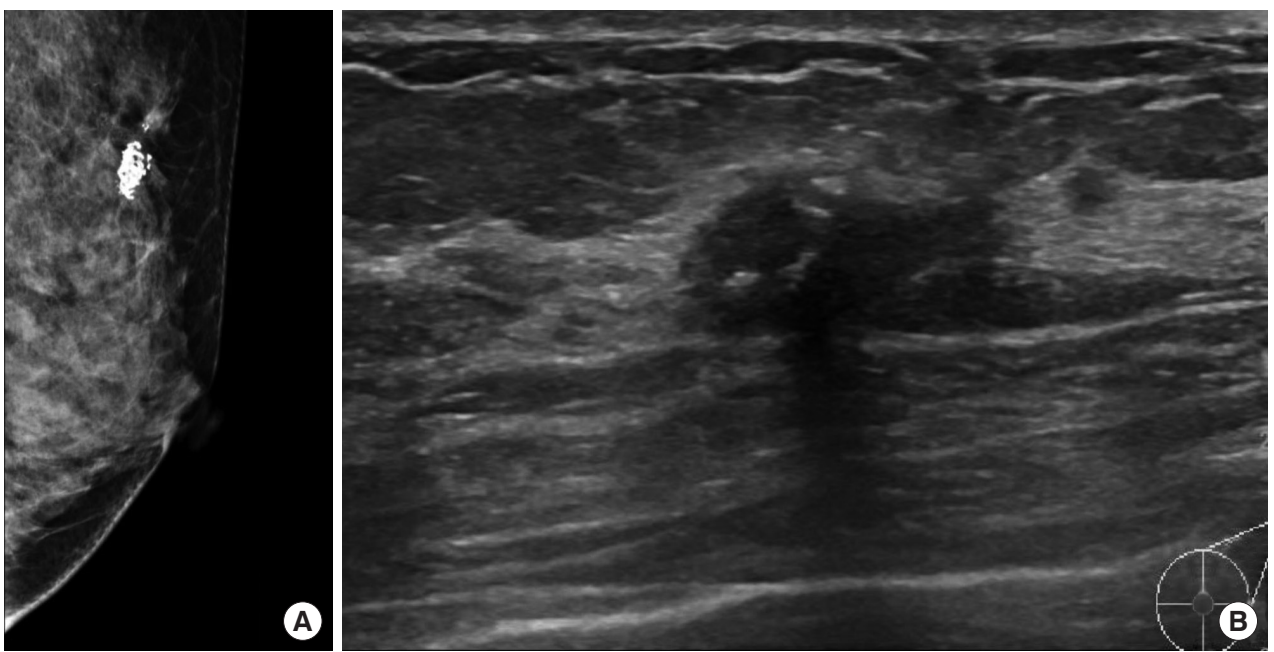

Figure 1. (A) Mammography reveals an oval calcified mass with partially indistinct margins. (B) Breast ultrasonography reveals a 1.7-cm irregular indistinct hypoechoic mass with calcifications.
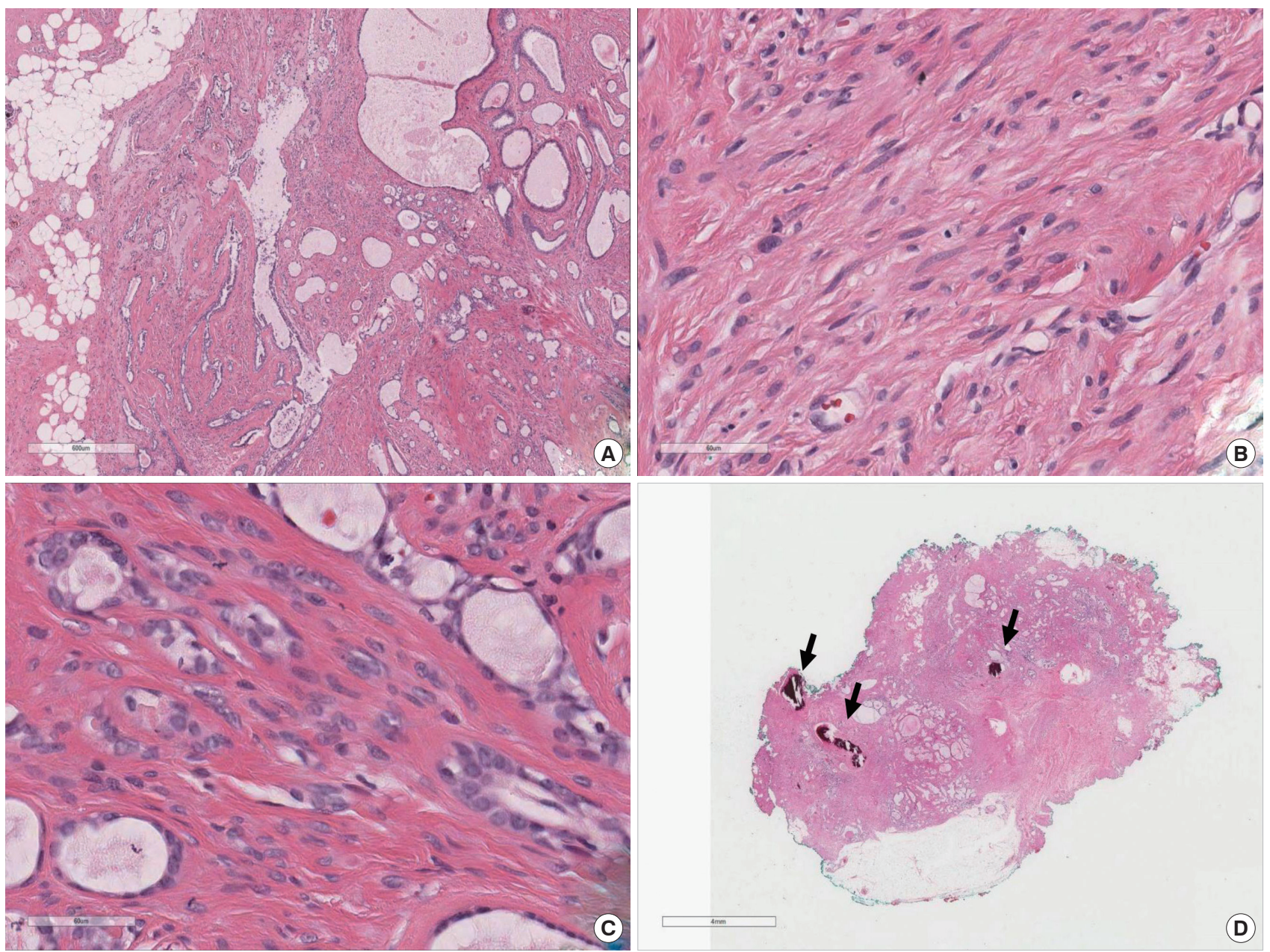

(D)

Figure 2. Microscopical findings. (A) The mass comprises glandular structures, fibrous stroma, and mature adipose in various proportions (hematoxylin and eosin [HE stain], $\times 40$ ). (B) The stroma reveals areas with high collagen concentration and elongated spindle cells without atypia (HE stain, $\times 400)$. (C) The spindle cells are intermixed with glandular elements (HE stain, $\times 400$ ). (D) Scan view shows an irregular mass with microcalcifications (arrows) (HE stain, $\times 4$ ). 

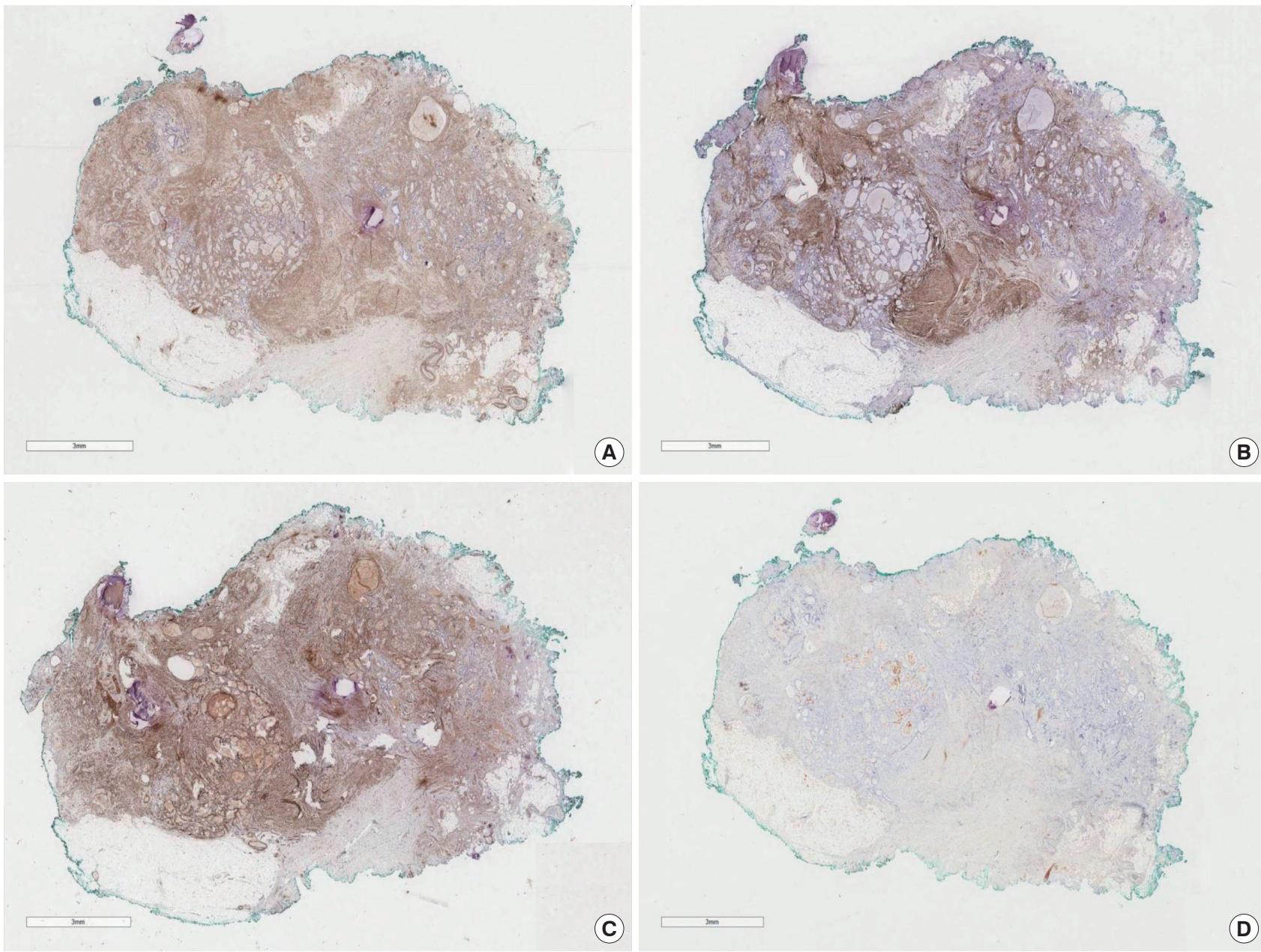

Figure 3. Immunohistochemical findings. (A) Smooth muscle actin, (B) desmin, and (C) smooth muscle myosin heavy chain are strongly positive in spindle cells, while (D) S-100 protein is negative.

spindle cells characterized by actin, desmin, and smooth muscle myosin heavy chain expression (Figure 3A-C). In contrast, both CD34 and S-100 protein expressions were negative (Figure 3D). Estrogen receptor staining showed positive expression in glandular elements and spindle cells. Histological and immunohistochemical findings were consistent with myoid hamartoma of the breast. The patient fully recovered 21 months postoperatively, with no tumor recurrence.

\section{DISCUSSION}

Breast hamartoma tends to be under-recognized despite the advent of diagnostic procedures such as mammography, breast ultrasonography, and core needle biopsy [10]. Since very few cases have been reported in the literature and increased number of cases are expected in the future, the pathologists should be aware of this type of lesion and its characteristics to avoid erroneous diagnosis.

Moreover, the pathogenesis of the myoid component in myoid hamartoma remains unclear. Various hypotheses have been proposed to explain the origin of smooth muscle stroma, and it is considered that it possibly originates from the myoepithelial cells, stromal myofibroblasts, vascular smooth muscle cells, or stromal stem cells $[4-6,8,10,13]$. Rosen et al. suggested that myoid hamartomas represent adenosis tumor with leiomyomatous metaplasia of the myoepithelial cells [1].

Clinically, most myoid hamartomas are asymptomatic and are detected on mammography or breast ultrasonography $[4,9]$. If clinically evident, myoid hamartoma presents as a well-circumscribed, firm, and mobile nodular mass, which is indistinguishable from other benign breast lesions. Mammography and ultrasonography confirm the 
presence of a clearly defined solid mass, occasionally with intralesional heterogeneous density, but are not diagnostic. Microcalcifications are usually not detected, but they can be observed in old lesions [11]. The findings of the present case are different from those of previous reports of myoid hamartoma. Mammography and ultrasonography revealed a partly irregular indistinct mass with microcalcifications. Clinically, breast cancer was not completely excluded. For the exact diagnosis, mass excision and histological examination were performed.

The histological composition of myoid hamartoma varies depending on the relative proportion of glandular, adipose, fibrous, and myomatous elements [1]. In most lesions, interlacing bundles of smooth muscle comprise focal leiomyoma formation, whereas in a minority of tumors, the myoid component mingles more diffusely with adipose and fibrous elements [3-13]. Core biopsy may be useful for the diagnosis of myoid hamartoma. However, for the definite diagnosis of myoid hamartoma, some reports have recommended excisional biopsy to provide sufficient evidence for the pathological examination $[4,6,9,11]$. Immunohistochemical studies are also helpful in establishing a diagnosis of myoid hamartoma, and several reports have suggested that spindle tumor cells show strong positive staining for smooth muscle actin, desmin, and vimentin, and the absence of staining for cytokeratin and S-100 protein [4-6,8-10,13]. Estrogen and progesterone receptors are also expressed randomly $[5,13]$. In the present case, the stroma was stained strongly for actin, desmin, and smooth muscle myosin heavy chain, which is consistent with previous reports $[4-6,8-10,13]$.

The histological differential diagnoses of myoid hamartoma include various spindle cell tumors and tumor-like lesions showing specifically smooth muscle differentiation $[5,9,10,13]$. Except for myoid hamartoma, primarily myoid tumors of the breast comprise leiomyoma and leiomyosarcoma and are exceptionally rare [14]. The presence of entrapped normal mammary lobules between smooth muscle bundles rules out leiomyoma $[5,10]$. In contrast to leiomyoma, the smooth muscle component of myoid hamartoma is mixed with other elements such as adipose and glandular tissues. The malignant features of leiomyosarcoma, nuclear atypia, mitotic activity, and necrosis, are not observed in myoid hamartoma [14]. Fibroadenoma and myofibroblastoma can also demonstrate myoid differentiation [14]. The absence of a peri- or intra-canalicular growth pattern differentiates myoid hamartoma from fibroadenoma [5,10,13]. In leiomyomatous myofibroblastoma, smooth muscle cells comprise the majority of the tumor, while other components such as adipose and glandular tissues are more prominent in myoid hamartoma [14]. Other mammary lesions with spindle cells, such as schwannoma and fibromatosis, may resemble myoid hamartoma $[5,10,13]$. Schwannoma is characterized by the expression of S-100 protein, which is negative in myoid hamartoma. Fibromatosis shows an infiltrative growth pattern and variable cellularity, which are not observed in myoid hamartoma. Diagnosis of myoid hamartoma can be difficult, particularly on core biopsy, but accurate diagnosis of myoid hamartoma is essential to distinguish other breast lesions with recurrence potential or more aggressive behavior [14].

Local excision is the treatment of choice for myoid hamartoma. However, there are case reports showing coincidental cancer or local recurrence after surgery $[6,8,11]$. Incomplete excision may be a contributing factor for local recurrence [8]. Therefore, complete excision with clear margins is appropriate for the treatment of myoid hamartoma. No adjuvant therapy is needed following appropriate surgery. The patient in the present case was well and did not experience tumor recurrence 21 months postoperatively.

Here, we report a rare case of mammary myoid hamartoma showing irregular margins and microcalcifications.

\section{CONFLICT OF INTEREST}

The authors declare that they have no competing interests.

\section{REFERENCES}

1. Hoda SA, Brogi E, Koerner FC, Rosen PP. Rosen's breast pathology. 4th ed. Philadelphia: Lippincott Williams \& Wilkins; 2014. P. 1056-60.

2. Lokuhetty D, White VA, Watanabe R, Cree IA. WHO classification of tumours: breast tumors. 5th ed. Lyon: IARC Press; 2019. P. 166-7.

3. Davies JD, Riddell RH. Muscular hamartomas of the breast. J Pathol 1973;11:209-11.

4. Stafyla V, Kotsifopoulos N, Grigoriadis K, Bakoyiannis CN, Peros G, Sakorafas GH. Myoid hamartoma of the breast: a case report and review of the literature. Breast J 2007;13:85-7.

5. Kajo K, Zubor P, Danko J. Myoid (muscular) hamartoma of the breast: case report and review of the literature. Breast Care 2010;5: $331-4$. 
6. Ko MS, Jung WS, Cha ES, Choi HJ. A rare case of recurrent myoid hamartoma mimicking malignancy: imaging appearances. Korean J Radiol 2010;11:683-6

7. Bayar S, Düşünceli E, Heper AO, Güner R, Genç V, Demirkazik A. Myoid hamartoma of the breast: a very rare entity. Breast J 2010;16: 86-8.

8. Yu L, Yang W, Xu X, Gu Y, Wang C, Lu H, et al. Myoid harmatoma of the breast: clinicopathologic analysis of a rare tumor indicating occasional recurrence potential. Breast J 2011;17:322-4.

9. Mizuta N, Sakaguchi K, Mizuta M, Imai A, Nakatsukasa K, Morita M, et al. Myoid hamartoma of the breast that proved difficult to diagnose: a case report. World J Surg Oncol 2012;10:12.
10. Nangia A, Patiri K, Pujani M, Sehgal S. Bilateral myoid hamartoma of breast: an exceptionally rare lesion. Breast Dis 2013;34:77-80.

11. Su CC, Chen CJ, Kuo SJ, Chen DR. Myoid hamartoma of the breast with focal chondromyoxid metaplasia and pseudoangiomatous stromal hyperplasia: a case report. Oncol Lett 2015;9:1787-9.

12. Felipe LJ, Sirkin W, Hanna WM. Myoid hamartoma of the breast with symplastic changes. Breast J 2016;22:583-4.

13. Xia T, Qin C, Long H, Zhou T, Xiao X. Mammary myoid hamartomas: reports of two cases and a review of the literature. Int J Clin Exp Pathol 2019;12:2398-404.

14. Krings G, McIntire P, Shin SJ. Myofibroblastic, fibroblastic and myoid lesions of the breast. Semin Diagn Pathol 2017;34:427-37. 